\title{
Pengaruh Persentase Arang Tempurung Kemiri Terhadap Nilai Kalor Briket Campuran Biomassa Ampas Kelapa - Arang Tempurung Kemiri
}

\author{
Ida Bagus Gde Gianyar*, Nurchayati ${ }^{\star \star}$, Yesung Allo Padang ${ }^{\star \star \star}$ \\ Jurusan Teknik Mesin Fakultas Teknik Universitas Mataram \\ Jl. Majapahit No.62 Mataram Nusa Tenggara Barat Kode Pos: 83125 \\ Telp. (0370) 636087; 636126; ext 128 Fax (0370) 636087
}

\begin{abstract}
Indonesia has many sources of renewable energy. One of the source renewable energy in Indonesia is biomass, because the price of biomass is relatively cheap and so far abundant numbers. Coconut dregs and hazelnut shell are biomass where these can't be utilized optimally. Biomass can be made into briquettes which is a fuel with high calorific value.

The method used in this study is an experimental method. Begining the process with manufacture of briquettes which is the drying process of coconut dregs and hazelnut shell using the sun until dry, then the process of composing hazelnut shell. Raw materials crushed and sieved, after that the raw material made into briquettes by varying the percentage composition of coconut dregs and charcoal hazelnut shell as follows $80 \%: 20 \%, 60 \%: 40 \%, 40 \%: 60 \%$, 20\%: $80 \%$. Then, the briquettes are tested their calorific value and moisture content.

The results show that higher heating value (HHV) and lower heating value (LHV) are the highest in the mix of AK 20\%: ATK $80 \%$ is equal to $34,517 \mathrm{~kJ} / \mathrm{gr}(8.242,819 \mathrm{cal} / \mathrm{gr})$ and $34,172 \mathrm{~kJ} / \mathrm{gr}(8.160,523 \mathrm{cal} / \mathrm{gr})$. Meanwhile the briquettes moisture content range between $2,474 \%-3,186 \%$ with average of $2,836 \%$. In term of calorific value and moisture content, biomass briquettes from coconut dregs and charcoal hazelnut shell meets the quality standards set by the standards of Indonesia, Britain, Japan and USA.
\end{abstract}

Key word : biomass, briquettes, calorific value, moisture content.

\section{Pendahuluan}

Krisis bahan bakar minyak kini sedang mengancam Indonesia. Salah satu penyebabnya tidak lain karena pertumbuhan konsumsi yang sangat cepat. Apalagi saat ini harga BBM di pasar dunia berada pada kisaran US $\$ 125$ - $\$ 140$ per barel (Ritonga, 2008:1). Hal ini membuat pemerintah kian terjepit karena secara otomatis dana subsidi BBM akan semakin melangit. Di Indonesia, sumber utama energi dalam negeri masih bertumpu pada jenis bahan bakar minyak, padahal banyak sumber energi alternatif lainnya yang dapat dimanfaatkan bahkan mampu menggantikan peran energi fosil tersebut (Suryanto, 2005:1).

Menurut Kepala Pusat Studi Energi (PSE) UGM, Prof. Dr. Jumina (2011:1), cadangan minyak bumi di Indonesia yang berjumlah 9 miliar barel akan habis dalam 23 tahun ke depan jika tidak ditemukan sumursumur minyak yang baru. Indonesia harus mulai mendorong efisiensi energi di segala bidang. Penghematan energi diharapkan mampu menghindarkan bangsa ini dari krisis energi. Perilaku hemat energi hendaknya menjadi budaya setiap warga negara. Jika masyarakat dan seluruh institusi telah menerapkan budaya hemat energi, maka cadangan energi yang ada di tanah air dapat dimanfaatkan dalam jangka waktu yang lebih lama.

Indonesia sesungguhnya banyak memiliki sumber energi terbarukan dalam jumlah yang besar. Salah satu sumber energi terbarukan yang berpotensi di Indonesia adalah biomassa. Momentum krisis BBM saat ini merupakan waktu yang tepat untuk menata dan menerapkan dengan serius potensi tersebut. Indonesia sebagai negara agraris memiliki lahan yang luas untuk membudidayakan tanaman-tanaman yang potensial sebagai bahan baku biomassa seperti kelapa dan kemiri.

Kelapa merupakan tanaman perkebunan/industri berupa pohon batang lurus dari Family Palmae. Tumbuhan ini dapat dimanfaatkan hampir semua bagiannya oleh manusia sehingga dianggap sebagai tumbuhan serbaguna (Anonim 4, 2011:1). Salah satu usaha yang dapat dilakukan untuk mencari sumber bahan bakar alternatif adalah dengan melakukan pengolahan terhadap ampas kelapa. Ampas kelapa merupakan hasil sampingan pembuatan miyak kelapa. Ampas kelapa yang telah diubah menjadi briket biomassa memilki nilai kalor sebesar 7.245,992 kal/gr (Wahab, 2010:15).

Sedangkan kemiri juga merupakan tanaman perkebunan yang termasuk dalam 
Family Euphorbiaceae. Kemiri mempunyai 2 lapis kulit yaitu kulit buah dan tempurung, dari setiap kilogram biji kemiri akan dihasilkan $30 \%$ inti dan $70 \%$ tempurung. Tempurung kemiri yang selama ini banyak dijadikan limbah, sebenarnya mempunyai kegunaan yang cukup bermanfaat. Pemanfaatannya selama ini hanya dijadikan sebagai bahan bakar untuk memasak biji kemiri, pengeringan kemiri isi dengan sistem pengasapan, dibuang dan sebagian dijual (Darmawan, 2005:71). Tempurung kemiri sebenarnya mempunyai prospek yang bagus untuk dijadikan sebagai bahan bakar alternatif karena arang tempurung kemiri yang sudah dijadikan briket memiliki nilai kalor sebesar 7.958,33 kal/gr (Sihombing, 2006:65).

peneliti tertarik untuk mencoba mengkombinasikan ampas kelapa dan arang tempurung kemiri tersebut menjadi bahan bakar alternatif dalam bentuk briket sebagai pengganti BBM dengan memvariasikan persentase komposisi bahan baku pembuatan briket terhadap besarnya nilai kalor dan kadar air briket.

\section{Landasan Teori}

Bahan bakar adalah suatu materi yang dapat diubah menjadi energi. Biasanya bahan bakar mengandung energi panas yang dapat dilepaskan dan dimanipulasi.

Klasifikasi bahan bakar berdasarkan

bentuknya dibedakan menjadi 3 yaitu:

1. Bahan bakar padat

Bahan bakar padat merupakan bahan bakar berbentuk padat, dan kebanyakan menjadi sumber energi panas misalnya kayu dan batubara.

2. Bahan bakar cair

Bahan bakar yang berbentuk cair, paling populer adalah bahan bakar minyak atau BBM. Selain dapat digunakan untuk memanaskan air menjadi uap, bahan bakar cair biasa digunakan oleh kendaraan bermotor. Karena bahan bakar cair seperti bensin bisa dibakar dalam karburator dan menjalankan mesin.

3. Bahan bakar gas

Bahan bakar gas ada dua jenis, yakni Compressed Natural Gas (CNG) dan Liquefied Petroleum Gas (LPG). CNG pada dasarnya terdiri dari metana sedangkan LPG adalah campuran dari propana, butana dan bahan kimia lainnya. LPG yang digunakan untuk kompor rumah tangga, sama bahannya dengan bahan bakar gas yang biasa digunakan untuk sebagian kendaraan bermotor (Anonim 2, 2011:1).

Biomassa merupakan bahan-bahan organik berumur relatif muda dan berasal dari tumbuhan atau hewan dan limbah industri budidaya (pertanian, perkebunan, kehutanan, perternakan, dan perikanan). Unsur utama dari biomassa adalah bermacam-macam zat kimia (molekul) yang sebagian besar mengandung atom karbon (C). Biomassa secara garis besar tersusun dari selulosa dan lignin (sering disebut ligninselulosa). Komposisi elementer biomassa kira-kira 53\% karbon, $6 \%$ hidrogen dan $42 \%$ oksigen, serta sedikit nitrogen, fosfor dan belerang (biasanya masing-masing kurang dari 1\%) (Supriyatno, dan Crishna, 2010: IO1-2). Biomassa tersebut dapat diolah menjadi bioarang, yang merupakan bahan bakar dengan tingkat nilai kalor yang cukup tinggi dan dapat digunakan dalam kehidupan sehari-hari (Subroto, 2006:48).

Beberapa penerapan teknologi konversi biomassa yaitu:

1. Densifikasi

Praktek yang mudah untuk meningkatkan manfaat biomassa adalah membentuk menjadi briket atau pellet.

2. Karbonisasi

Karbonisasi merupakan suatu proses untuk mengkonversi bahan organik menjadi arang. Pada proses karbonisasi akan melepaskan zat yang mudah terbakar seperti $\mathrm{CO}, \mathrm{CH}_{2}, \mathrm{H}_{2}$, formaldehid, methana, formik dan acetil acid serta zat yang tidak terbakar seperti $\mathrm{CO}_{2}, \mathrm{H}_{2} \mathrm{O}$ dan tar cair.

3. Pirolisis

Pirolisis atau juga disebut thermolisis adalah proses dekomposisi kimia dengan menggunakan pemanasan tanpa kehadiran oksigen. Proses ini sebenarnya bagian dari proses karbonisasi yaitu proses untuk memperoleh karbon atau arang, tetapi sebagian menyebut pada proses pirolisis merupakan high temperature carbonization (HTC), lebih dari $500^{\circ} \mathrm{C}$. (Pambudi, 2008:1).

Briket adalah suatu padatan yang dihasilkan melalui proses pemampatan tekanan dan jika dibakar menghasilkan sedikit asap (Supriyatno dan Crishna, 2010:101-3). Pembriketan bertujuan untuk memperoleh suatu bahan bakar yang berkualitas yang dapat digunakan untuk semua sektor sebagai sumber energi pengganti (alternatif). Briket dibuat dari limbah serbuk batu bara, coke, 
serbuk gergajian kayu (sawdust) dan arang kayu dengan bahan pengikat (binder) seperti petrolium asphal atau coalter (bahan tetes gula).

Briket dibuat dalam cetakan yang berbentuk kubus atau silinder dengan ukuran beragam. Dengan cara pembuatan di atas maka briket akan mempunyai karakteristik:

1. Cukup kuat terhadap handling.

2. Mempunyai bentuk seragam.

3. Tahan terhadap kelembaban udara.

Dengan memperhatikan hal di atas, briket hanya sesuai untuk keperluan industri kecil dan rumah tangga. Nilai kalor briket sangat beragam sesuai dengan bahan bakunya (Tjokrowisastro dan Widodo, 1990:30).

Menurut Indriyatmoko dkk (2010:MI531), ada beberapa kelebihan briket dibandingkan dengan bahan bakar padat yang lain adalah:

1. Lebih hemat dan irit.

2. Panas lebih tinggi.

3. Nyala bara cukup lama dan tidak berjelaga sehingga peralatan masak tetap bersih.

4. Aman (tidak beracun dan tidak meledak).

5. Abu briket dapat dimanfaatkan sebagai pupuk.

Briket yang baik harus memenuhi standar yang telah ditentukan agar dapat dipakai sesuai dengan keperluannya. Penentuan kualitas briket arang umumnya dilakukan terhadap komposisi kimia seperti kadar abu, kadar zat mudah menguap, kadar karbon terikat dan sifat fisika seperti kadar air, berat jenis, nilai kalor serta sifat mekanik. Kualitas briket arang yang berada di pasaran dapat dilihat pada tabel 1 berikut.
Arang adalah residu hitam berisi karbon tidak murni yang dihasilkan dengan menghilangkan kandungan air dan komponen volatile dari hewan atau tumbuhan. Arang umumnya didapatkan dengan memanaskan kayu, tulang, dan benda lain. Arang yang hitam, ringan, mudah hancur, dan menyerupai batu bara ini terdiri dari $85 \%$ sampai $98 \%$ karbon, sisanya adalah abu atau unsur kimia lainnya (Anonim 1, 2011:1).

Proses pengarangan terjadi bila ada suatu benda yang dipanasi sampai mencapai titik bakarnya sehingga benda terlihat membara, kemudian pemasukan oksigen dihentikan / dibatasi dengan menutup sebagian lubang agar benda tersebut tidak terbakar menjadi abu (Suheryanto, dan Haryanto, 2004:1-2-2). Proses pengarangan ternyata mampu meningkatkan nilai kalor dan kadar karbon terikat serta mampu menurunkan kadar air, kadar abu, dan kadar zat terbang (Darmawan, 2005:72).

Nilai kalor bahan bakar adalah jumlah energi panas maksimum yang dibebaskan oleh suatu bahan bakar melalui reaksi pembakaran sempurna persatuan massa atau volume bahan bakar tersebut. Analisa nilai kalor suatu bahan bakar dimaksudkan untuk memperoleh data tentang energi kalor yang dapat dibebaskan oleh suatu bahan bakar dengan terjadinya reaksi atau proses pembakaran (Tjokrowisastro dan Widodo, 1990: 85). Alat yang digunakan untuk mengukur nilai kalor dinamakan bomb calorimeter. Bomb calorimeter bekerja dengan prinsip adiabatik, yang berarti tidak ada kalor yang masuk ataupun keluar dari sistem, sehingga kondisinya ideal (Anonim 3, 2011:1).

Tabel 1. Kualitas briket arang

\begin{tabular}{lcccc}
\hline Sifat-Sifat Briket Arang & Jepang & Inggris & USA & Indonesia \\
\hline Kadar Air (\%) & $6-8$ & $3-4$ & 6 & 7,57 \\
\hline Kadar Zat Mudah Menguap (\%) & $15-30$ & 16 & 19 & 16,14 \\
\hline Kadar Abu (\%) & $3-6$ & $8-10$ & 18 & 5,51 \\
\hline Kadar Karbon Terikat (\%) & $60-80$ & 75 & 58 & 78,35 \\
\hline Nilai Kalor (kal/gr) & $6000-7000$ & 7300 & 6500 & 6814,11 \\
\hline Kerapatan (gr/cm $\left.{ }^{3}\right)$ & $1-2$ & 0,84 & 1 & 0,4407 \\
\hline Keteguhan Tekan (kg/cm²) & 60 & 12,7 & 62 & 0,46 \\
\hline
\end{tabular}

(Sumber: Hendra,1999 dalam Sunyata, dan Wulur, 2008:2)

Dengan menggangap bahwa bomb calorimeter terisolasi sempurna dari sekitar, maka hukum kekekalan energi pada sistem adalah energi yang dibebaskan oleh proses pembakaran sama dengan energi yang diserap oleh air dan perangkat kalorimeter (Tjokrowisatro dan Widodo, 1990: 87).

Nilai kalor atas (NKA) suatu bahan bakar dapat dihitung menggunakan persamaan: 


$$
\mathrm{NKA}_{\mathrm{bb}}=\frac{\left[\left(\mathrm{m}_{\mathrm{a}}+\mathrm{M}_{\mathrm{k}}\right) \mathrm{c}_{\mathrm{pa}} \cdot \Delta \mathrm{T}_{\mathrm{a}}\right]-\left[\Delta \mathrm{L}_{\mathrm{p}} \cdot \mathrm{NK}_{\mathrm{p}}\right]}{\mathrm{m}_{\mathrm{bb}}}
$$

Dimana:

$\left(\mathrm{m}_{\mathrm{a}}+\mathrm{M}_{\mathrm{k}}\right) \cdot \mathrm{c}_{\mathrm{pa}}=10.341,396 \mathrm{~J} /{ }^{\circ} \mathrm{C}$.

Nilai $10.341,396 \mathrm{~J} /{ }^{\circ} \mathrm{C}$ adalah nilai ketetapan yang digunakan setiap bahan yang dibakar untuk menaikan $1^{\circ} \mathrm{C}$ temperatur air dan perangkat kalorimeter.

$\mathrm{NKA}_{\mathrm{bb}}=$ nilai kalor atas bahan bakar $(\mathrm{J} / \mathrm{gr})$

$\mathrm{NK}_{\mathrm{p}} \quad=$ nilai kalor pematik (kalor lebur)

$=2,3 \mathrm{kal} / \mathrm{cm}=9,6296 \mathrm{~J} / \mathrm{cm}$.

$\Delta \mathrm{L}_{\mathrm{p}}=$ panjang kawat pematik yang terbakar (cm)

$\mathrm{m}_{\mathrm{a}} \quad$ = massa air dalam bejana (2.000 gr)

$\mathrm{M}_{\mathrm{k}} \quad=$ nilai tara air kalorimeter $(473,781$ gr)

$\mathrm{c}_{\mathrm{pa}} \quad=$ panas jenis air $\left(3,1804 \mathrm{~J} / \mathrm{gr}^{\circ} \mathrm{C}\right.$ pada $\mathrm{T}=25^{\circ} \mathrm{C}$, tekanan $\left.1 \mathrm{~atm}\right)$

$\Delta \mathrm{T}_{\mathrm{a}} \quad=$ kenaikan suhu yang terkoreksi $\left({ }^{\circ} \mathrm{C}\right)$

Sedangkan nilai kalor bawah dihitung dengan persamaan:

$$
\mathrm{NKB}_{\mathrm{bb}}=\mathrm{NKA}_{\mathrm{bb}}-\mathrm{x} \cdot \mathrm{LH}
$$

Dimana:

$\mathrm{NKB}_{\mathrm{bb}}=$ nilai kalor bawah bahan bakar $(\mathrm{J} / \mathrm{gr})$

$\mathrm{X}=$ massa $\mathrm{H}_{2} \mathrm{O}$ yang terkondensasi per massa bahan bakar (gr $\mathrm{H}_{2} \mathrm{O} / \mathrm{gr}$ bahan bakar)

$\mathrm{LH} \quad=$ panas laten penguapan $\mathrm{H}_{2} \mathrm{O}$ diukur pada suhu $25^{\circ} \mathrm{C}$ yaitu $2.442,3 \mathrm{~J} / \mathrm{gr}$

Analisa kadar air suatu bahan bakar dimaksudkan untuk memperoleh data tentang kadar air yang dapat mempengaruhi besarnya energi kalor pada bahan bakar tersebut. Untuk mengetahui kadar air dari suatu bahan bakar padat maka dilakukan pengovenan dengan menggunakan oven listrik, kemudian dianalisis dengan menggunakan persamaan berikut:

$\%$ kadar air $\quad=\frac{m_{\mathrm{b}}-\mathrm{m}_{\mathrm{k}}}{\mathrm{m}_{\mathrm{s}}} \times 100 \%$

$\%$ bahan kering $=100 \%-\%$ kadar air (4) Dimana:

Massa sampel $\left(\mathrm{m}_{\mathrm{s}}\right)=$ massa cawan dan sampel dikurangi massa cawan kosong (gr).

Massa basah $\left(\mathrm{m}_{\mathrm{b}}\right)=$ massa cawan dan sampel sebelum dioven ( $\mathrm{gr}$ ).

Massa kering $\left(\mathrm{m}_{\mathrm{k}}\right)=$ massa cawan dan sampel setelah dioven pada suhu $105^{\circ} \mathrm{C}$ (gr).

\section{Metode Penelitian}

Dalam penelitian ini terdapat dua macam pengujian yaitu pengujian nilai kalor dan pengujian kadar air. Pengujian nilai kalor dilakukan dengan menggunakan bomb calorimeter yang bertujuan untuk mengetahui nilai kalor atas (NKA) dan nilai kalor bawah (NKB) briket yang dihasilkan pada pembakaran sempurna persatuan massa bahan bakar. Sedangkan pengujian kadar air dilakukan dengan menggunakan oven pengering yang bertujuan untuk mengetahui persentase kadar air yang terkandung dalam briket sehingga persentase bahan keringnya dapat diketahui.

Bahan baku yang digunakan dalam penelitian ini adalah ampas kelapa dan tempurung kemiri yang sudah dijadikan arang. Proses awal pembuatan briket yaitu proses pengeringan ampas kelapa dan tempurung kemiri dengan menggunakan sinar matahari hingga kering kemudian dilanjutkan dengan proses pengarangan tempurung kemiri. Bahan baku tersebut kemudian ditumbuk atau dihaluskan dengan menggunakan lumpang dan antan (alu) lalu kemudian diayak agar memperoleh ukuran partikel yang homogen (seragam). Proses pencampuran kedua bahan baku tersebut dilakukan setelah semua bahan baku ditimbang dengan persentase ampas kelapa dan arang tempurung kemiri yaitu:

* AK 100\% (90 gram ampas kelapa)

* AK 80\% : ATK 20\% (72 gram ampas kelapa : 18 gram arang tempurung kemiri)

* AK 60\% : ATK 40\% (54 gram ampas kelapa : 36 gram arang tempurung kemiri)

* AK 40\% : ATK 60\% (36 gram ampas kelapa : 54 gram arang tempurung kemiri)

* AK 20\%: ATK 80\% (18 gram ampas kelapa : 72 gram arang tempurung kemiri)

* ATK 100\% (90 gram arang tempurung kemiri)

Pada setiap perbandingan (campuran 90 gram ampas kelapa dan arang tempurung kemiri) tersebut kemudian dicampur dengan perekat kanji dengan perbandingan $15: 1$ (90 gram total massa campuran : 6 gram kanji) dan ditambahkan air panas secukupnya yaitu sekitar 55,5 ml. Bahan-bahan tersebut kemudian diaduk hingga tercampur rata dan dicetak menggunakan alat cetak briket berbentuk silinder lalu kemudian dikeringkan dengan menggunakan sinar matahari selama beberapa hari hingga benar-benar kering. Setelah briket tersebut kering kemudian dilakukan pengujian nilai kalor dan kadar air.

\section{Hasil dan Pembahasan}

Pengujian nilai kalor dilakukan dengan menggunakan alat bomb calorimeter yang tujuannya untuk mengetahui besar nilai kalor yang terdapat pada briket yang terdiri atas nilai kalor atas (NKA) dan nilai kalor bawah (NKB). Data hasil pengujian nilai kalor briket campuran biomassa ampas kelapa arang tempurung kemiri dapat dilihat pada tabel 2. 
Tabel 2. Nilai kalor rata-rata briket campuran biomassa ampas kelapa - arang tempurung kemiri

\begin{tabular}{|c|c|c|c|c|c|c|c|c|}
\hline $\begin{array}{l}\text { Kode } \\
\text { sampel }\end{array}$ & $\begin{array}{l}\mathbf{m}_{\mathbf{b b}} \\
(\mathrm{gr})\end{array}$ & $\begin{array}{c}\Delta \mathrm{T} \\
\left({ }^{\circ} \mathrm{C}\right)\end{array}$ & $\begin{array}{l}\Delta \mathbf{L}_{\mathbf{p}} \\
(\mathrm{cm})\end{array}$ & $\begin{array}{c}\mathbf{x}_{\mathrm{H}_{2} \mathrm{O}} \\
(\mathrm{gr})\end{array}$ & $\begin{array}{l}N^{N_{1} A_{b b}} \\
(\mathrm{~kJ} / \mathrm{gr})\end{array}$ & $\begin{array}{l}\mathbf{N K A}_{\text {bb }} \\
\text { (kal/gr) }\end{array}$ & $\begin{array}{l}N^{N^{\prime} B_{b b}} \\
(\mathrm{~kJ} / \mathrm{gr})\end{array}$ & $\begin{array}{l}N^{N_{B} B_{b b}} \\
\text { (kal/gr) }\end{array}$ \\
\hline AK $100 \%$ & 1,062 & 3 & 6,43 & 0,329 & 29,159 & $6.963,121$ & 28,355 & $6.771,364$ \\
\hline $\begin{array}{l}\text { AK : ATK } \\
80 \%: 20 \%\end{array}$ & 1,078 & 3,33 & 7,46 & 0,227 & 31,908 & $7.619,633$ & 31,352 & $7.486,876$ \\
\hline $\begin{array}{l}\text { AK : ATK } \\
60 \%: 40 \%\end{array}$ & 1,086 & 3,5 & 7,03 & 0,163 & 33,266 & $7.944,127$ & 32,866 & $7.848,534$ \\
\hline $\begin{array}{l}\text { AK : ATK } \\
40 \%: 60 \%\end{array}$ & 1,088 & 3,56 & 7,7 & 0,179 & 33,836 & $8.080,168$ & 33,397 & $7.975,470$ \\
\hline $\begin{array}{l}\text { AK : ATK } \\
20 \%: 80 \%\end{array}$ & 1,086 & 3,63 & 7,73 & 0,141 & 34,517 & $8.242,819$ & 34,172 & $8.160,523$ \\
\hline ATK $100 \%$ & 1,079 & 3,66 & 7,33 & 0,174 & 35,066 & $8.373,839$ & 34,639 & $8.272,063$ \\
\hline
\end{tabular}

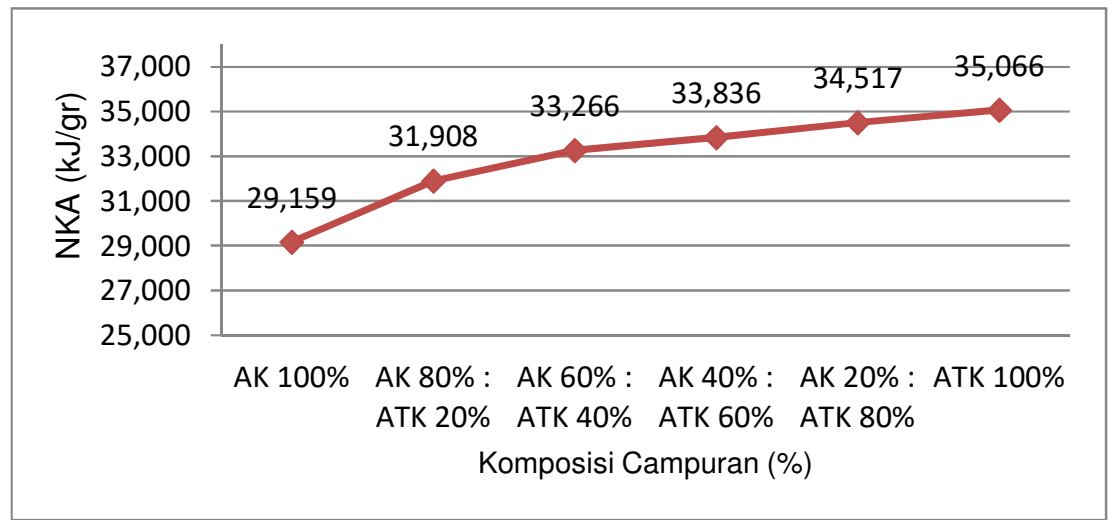

Gambar 1. Nilai kalor atas (NKA) briket campuran biomassa ampas kelapa - arang tempurung kemiri

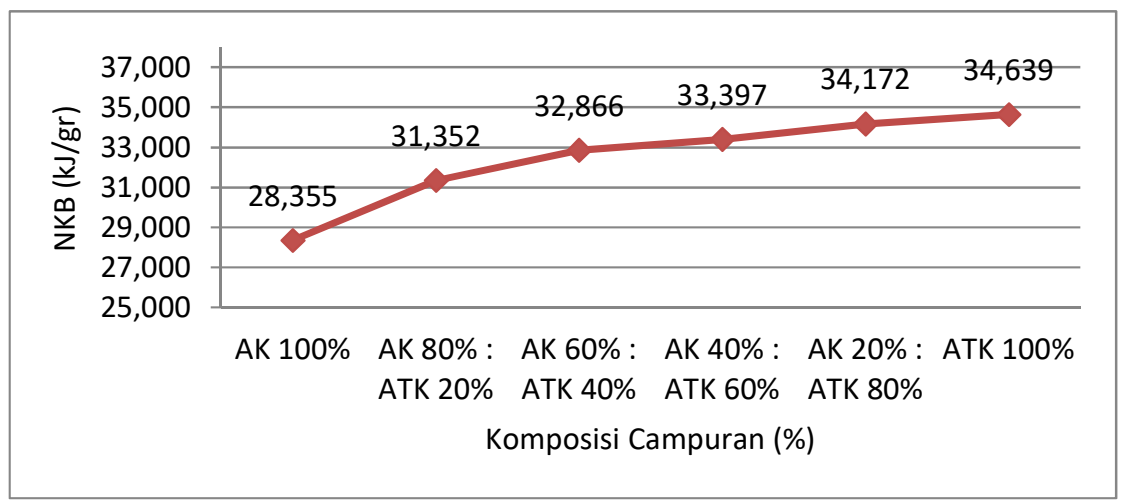

Gambar 2. Nilai kalor bawah (NKB) briket campuran biomassa ampas kelapa - arang tempurung kemiri

Dari gambar 1 dapat dilihat bahwa nilai kalor atas (NKA) briket pada masingmasing perlakuan (komposisi campuran) semakin meningkat seiring dengan bertambahnya persentase arang tempurung kemiri dalam briket. Hal ini disebabkan karena kadar karbon yang terkandung dalam briket semakin meningkat, karena setiap unsur karbon yang teroksidasi saat berlangsungnya proses pembakaran akan menghasilkan panas (kalor) sehingga berpengaruh terhadap peningkatan nilai kalor atas (NKA) briket tersebut.

Dari gambar 1 juga dapat dilihat bahwa briket campuran biomassa ampas kelapa - arang tempurung kemiri yang memiliki nilai kalor atas (NKA) tertinggi terdapat pada briket dengan campuran AK 
20\%: ATK $80 \%$ yaitu sebesar $34,517 \mathrm{~kJ} / \mathrm{gr}$ $(8.242,819 \mathrm{kal} / \mathrm{gr})$, sedangkan nilai kalor atas (NKA) terendah terdapat pada briket dengan campuran AK $80 \%$ : ATK $20 \%$ yaitu sebesar $31,908 \mathrm{~kJ} / \mathrm{gr}(7.619,633 \mathrm{kal} / \mathrm{gr})$.

Dari gambar 2 dapat dilihat bahwa nilai kalor bawah (NKB) briket pada masingmasing perlakuan (komposisi campuran) semakin meningkat seiring dengan bertambahnya persentase arang tempurung kemiri dalam briket. Hal ini disebabkan karena kadar karbon yang terkandung dalam briket semakin meningkat, karena setiap unsur karbon yang teroksidasi saat berlangsungnya proses pembakaran akan menghasilkan panas (kalor) sehingga berpengaruh terhadap peningkatan nilai kalor bawah (NKB) briket tersebut.

Besar nilai kalor bawah (NKB) yang dihasilkan oleh briket selain dipengaruhi oleh energi ataupun unsur-unsur yang terkandung dalam briket seperti kandungan karbon yang ada dalam briket, juga dipengaruhi oleh jumlah $\mathrm{H}_{2} \mathrm{O}$ yang terkondensasi yang merupakan salah satu hasil dari proses pembakaran briket yang tertampung dalam silinder bomb calorimeter. Dimana jumlah $\mathrm{H}_{2} \mathrm{O}$ yang terkondensasi setelah proses pembakaran tergantung dari besarnya kadar air dalam briket tersebut, apabila kadar air yang terkandung dalam briket semakin besar maka jumlah $\mathrm{H}_{2} \mathrm{O}$ yang terkondensasi setelah proses pembakaran akan semakin banyak sehingga akan diperoleh nilai kalor bawah (NKB) yang cenderung semakin rendah karena nilai kalor yang dihasilkan dari proses pembakaran sebagian digunakan untuk menguapkan $\mathrm{H}_{2} \mathrm{O}$ yang masih terkandung dalam briket dari fase cair ke fase gas.

Dari gambar 2 juga dapat dilihat bahwa nilai kalor bawah (NKB) tertinggi terdapat pada briket dengan campuran AK $20 \%$ : ATK $80 \%$ yaitu sebesar $34,172 \mathrm{~kJ} / \mathrm{gr}$ $(8.160,523 \mathrm{kal} / \mathrm{gr})$, sedangkan nilai kalor bawah (NKB) terendah terdapat pada briket dengan campuran AK 80\%: ATK 20\% yaitu sebesar 31,352 kJ/gr (7.486,876 kal/gr).

Tabel 3. Data rata-rata pengujian kadar air briket campuran biomassa ampas kelapa - arang tempurung kemiri

\begin{tabular}{|c|c|c|c|c|c|c|}
\hline $\begin{array}{l}\text { Kode } \\
\text { sampel }\end{array}$ & $\begin{array}{c}\text { Massa cawan } \\
\text { kosong }\left(\mathbf{m}_{\mathbf{c}}\right) \\
(\mathrm{gr})\end{array}$ & $\begin{array}{c}\text { Massa cawan } \\
\text { + sampel }\left(\mathbf{m}_{\mathbf{b}}\right) \\
\text { (gr) }\end{array}$ & $\begin{array}{c}\text { Massa sampel } \\
\left(\mathbf{m}_{\mathbf{s}}\right) \\
(\mathrm{gr})\end{array}$ & $\begin{array}{c}\text { Massa cawan }+ \\
\text { sampel setelah } \\
\text { suhu } 105^{\circ} \mathrm{C}\left(\mathbf{m}_{\mathbf{k}}\right) \\
(\mathrm{gr})\end{array}$ & $\begin{array}{l}\text { Kadar } \\
\text { air } \\
(\%)\end{array}$ & $\begin{array}{c}\text { Bahan } \\
\text { kering } \\
(\%)\end{array}$ \\
\hline AK 100\% & 22,632 & 23,873 & 1,241 & 23,835 & 3,186 & 96,814 \\
\hline $\begin{array}{l}\text { AK : ATK } \\
80 \%: 20 \%\end{array}$ & 19,677 & 20,701 & 1,024 & 20,671 & 2,981 & 97,019 \\
\hline $\begin{array}{c}\text { AK : ATK } \\
60 \%: 40 \%\end{array}$ & 20,656 & 21,876 & 1,220 & 21,843 & 2,681 & 97,318 \\
\hline $\begin{array}{cl}\text { AK } & : \text { ATK } \\
40 \% & : 60 \%\end{array}$ & 19,697 & 20,895 & 1,198 & 20,861 & 2,867 & 97,133 \\
\hline $\begin{array}{l}\text { AK : ATK } \\
20 \%: 80 \%\end{array}$ & 21,360 & 22,467 & 1,107 & 22,440 & 2,474 & 97,526 \\
\hline ATK $100 \%$ & 20,656 & 21,772 & 1,117 & 21,742 & 2,827 & 97,173 \\
\hline
\end{tabular}

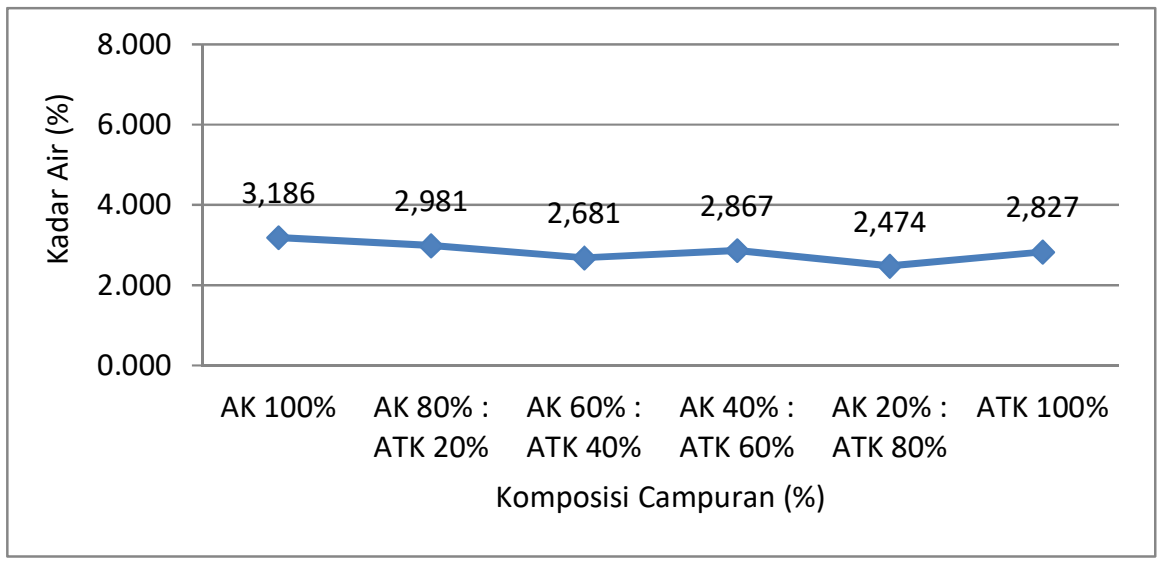

Gambar 3. Kadar air briket campuran biomassa ampas kelapa - arang tempurung kemiri 
Ditinjau dari segi nilai kalor, nilai kalor atas (NKA) dan nilai kalor bawah (NKB) briket campuran biomassa ampas kelapa - arang tempurung kemiri ini telah memenuhi standar kualitas briket menurut standar Indonesia, Inggris, Jepang dan USA yaitu berkisar antara $6.000-7.300 \mathrm{kal} / \mathrm{gr}$.

Pengujian kadar air pada briket dilakukan untuk mengetahui persentase kadar air yang terkandung pada briket yang nantinya akan menentukan kualitas briket tersebut. Data hasil pengujian kadar air briket campuran biomassa ampas kelapa-arang tempurung kemiri dapat dilihat pada tabel 3 .

Dari gambar 3 dapat dilihat bahwa dengan semakin meningkatnya persentase arang tempurung kemiri dalam briket maka kadar air briket semakin menurun hal ini disebabkan jumlah pori-pori pada briket semakin banyak seiring dengan semakin meningkatnya persentase arang tempurung kemiri dalam briket karena arang merupakan suatu padatan yang memiliki pori-pori yang cukup banyak. Hal ini mengakibatkan ketika berlangsung proses pengeringan kandungan air yang ada dalam briket akan lebih mudah untuk menguap.

Dari gambar 3 juga dapat dilihat bahwa persentase kadar air briket pada masing-masing perlakuan berkisar antara $3,186 \%-2,474 \%$ dengan rata-rata $2,836 \%$. Briket dengan persentase kadar air tertinggi dan briket dengan persentase kadar air terendah hanya berselisih 0,712\%. Persentase kadar air tertinggi terdapat pada briket dengan campuran AK 100\% yaitu $3,186 \%$, hal ini disebabkan karena sampel briket pada perlakuan ini memiliki jumlah poripori yang sedikit sehingga ketika berlangsungnya proses pengeringan kandungan air yang ada dalam briket sulit untuk menguap. Sedangkan persentase kadar air terendah terdapat pada briket dengan campuran AK 20\% : ATK 80\% yaitu $2,474 \%$.

Dari gambar 3 juga dapat dilihat bahwa briket pada perlakuan AK 40\% : ATK $60 \%$ dan ATK $100 \%$ persentase kadar airnya sedikit lebih besar daripada briket pada perlakuan AK 60\%: ATK 40\% dan AK 20\%: ATK $80 \%$, hal ini disebabkan karena kurang meratanya campuran bahan baku (adonan) briket saat proses pengadukan adonan briket terutama ketika penambahan air panas, adonan briket lebih cepat menggumpal ketika ditambahkan air panas sehingga proses pengadukan adonan untuk mendapatkan campuran yang homogen menjadi lebih sulit, sehingga hal ini mengakibatkan terjadinya penyerapan air yang berbeda-beda pada campuran bahan baku briket tersebut.

Ditinjau dari segi kadar air, persentase kadar air yang dimiliki oleh briket campuran biomassa ampas kelapa - arang tempurung kemiri ini telah memenuhi standar kualitas briket menurut standar Indonesia, Inggris, Jepang dan USA yaitu berkisar antara 3\% - 8\%.

\section{Kesimpulan}

1. Dengan semakin bertambahnya persentase arang tempurung kemiri dalam briket menyebabkan nilai kalor atas (NKA) briket campuran biomassa ampas kelapa - arang tempurung kemiri semakin meningkat. Briket yang memiliki nilai kalor atas (NKA) tertinggi terdapat pada campuran AK 20\%: ATK 80\% yaitu sebesar 34,517 kJ/gr (8.242,819 kal/gr), sedangkan briket yang memiliki nilai kalor atas (NKA) terendah terdapat pada campuran AK 80\%: ATK 20\% yaitu sebesar 31,908 kJ/gr (7.619,633 kal/gr).

2. Dengan semakin bertambahnya persentase arang tempurung kemiri dalam briket juga menyebabkan nilai kalor bawah (NKB) briket campuran biomassa ampas kelapa - arang tempurung kemiri semakin meningkat. Briket yang memiliki nilai kalor bawah (NKB) tertinggi terdapat pada campuran AK 20\% : ATK 80\% yaitu sebesar 34,172 $\mathrm{kJ} / \mathrm{gr}(8.160,523 \mathrm{kal} / \mathrm{gr})$, sedangkan briket yang memiliki nilai kalor bawah (NKB) terendah terdapat pada campuran AK $80 \%$ : ATK $20 \%$ yaitu sebesar 31,352 $\mathrm{kJ} / \mathrm{gr}(7.486,876 \mathrm{kal} / \mathrm{gr})$.

3. Persentase kadar air briket campuran biomassa ampas kelapa - arang tempurung kemiri pada masing-masing perlakuan berkisar antara $2,474 \%$ $3,186 \%$ dengan rata-rata $2,836 \%$.

\section{Saran}

1. Untuk proses pengeringan briket sebaiknya menggunakan oven listrik agar seluruh sampel briket mendapatkan intensitas panas yang sama dan konstan sehingga hasil proses pengeringan briket lebih bagus.

2. Untuk mendapatkan kualitas briket yang lebih baik perlu dilakukan proses pirolisis dengan temperatur tinggi pada briket campuran biomassa ampas kelapa arang tempurung kemiri ini.

3. Perlu dilakukan penelitian lebih lanjut mengenai uji emisi gas hasil pembakaran briket campuran biomassa 
ampas kelapa - arang tempurung kemiri ini.

4. Perlu dilakukan penelitian lebih lanjut mengenai lama nyala dari briket campuran biomassa ampas kelapa arang tempurung kemiri ini.

\section{Daftar Pustaka}

Anonim 1.,2011, Arang. http://www.wikipedia.org. Diunduh tanggal 15 Oktober 2011.

Anonim 2., 2011, Bahan Bakar. http://www.wikipedia.org. Diunduh tanggal 21 Oktober 2011.

Anonim 3., 2011, Kalorimeter. http://www.alatlabdankimia.wordpress .com. Diunduh tanggal 25 Oktober 2011.

Anonim 4., 2011, Kelapa. http://www.wikipedia.org. Diunduh tanggal 3 Oktober 2011.

Darmawan, S., 2005, Ragam Manfaat Kemiri, Balai Litbang Kehutanan, Mataram.

Indriyatmoko., Hutabarat, B., dan Pratiwi, D.K., 2010, Prospek Penggunaan Briket Batubara Sebagai Bahan Bakar Pengganti Minyak dan Gas, Jurusan Teknik Mesin Fakultas Teknik, Universitas Sriwijaya.

Jumina., 2011, Audit Energi Cegah Krisis Energi, Universitas Gadjah Mada. http://www.kmkimia.mipa.ugm.ac.id. Diunduh tanggal 3 Oktober 2011.

Pambudi, N.A., 2008, Energi Alternatif Itu Bernama Biomassa. http://www.netsains.com. Diunduh tanggal 21 Oktober 2011.

Ritonga, C., 2008, Krisis Minyak Global. http://www.waspada.co.id. Diunduh tanggal 3 Oktober 2011.
Sihombing, J.L., 2006, Studi Pembuatan Briket Arang dari Cangkang Kemiri Dengan Variasi Ukuran Partikel Arang dan Konsentrasi Perekat, Jurusan Kimia Fakultas MIPA, Universitas Negeri Medan.

Subroto., 2006, Karakteristik Pembakaran Biobriket Campuran Batubara, Ampas Tebu dan Jerami, Jurusan Teknik Mesin Fakultas Teknik, Universitas Muhammadiyah Surakarta.

Suheryanto, D., dan Haryanto, T., 2010, Arang Briket Biomassa Dari Sampah Kota Sebagai Bahan Bakar Alternatif, Jurusan Teknik Kimia Fakultas Teknik, Universitas Diponegoro Semarang.

Sunyata, A., dan Wulur, P.D., 2008, Pengaruh Kerapatan dan Suhu Pirolisa Terhadap Kualitas Briket Arang Serbuk Kayu Sengon, Fakultas Kehutanan Institut Pertanian Yogyakarta.

Supriyatno., dan Crishna, B.M., 2010, Studi Kasus Energi Alternatif Sampah Lingkungan Kampus POLBAN Bandung, Kelompok Energi-Pusat Penelitian Fisika-LIPI, Bandung.

Suryanto, S.B., 2005, Energi Alternatif dan Kemauan Politik Pemerintah. http://www.tech.groups.yahoo.com. Diunduh tanggal 3 Oktober 2011.

Tjokrowisastro, E.H., dan Widodo, B.U.K., 1990, Teknik Pembakaran Dasar dan Bahan Bakar, ITS, Surabaya.

Wahab, A., 2010, Pemanfaatan Ampas Kelapa Sebagai Bahan Bakar Alternatif, Jurusan Teknik Mesin Fakultas Teknik, Universitas Mataram. 